\title{
KEBIJAKAN HUTANG: STRUKTUR ASET, PROFITABILITAS DAN PELUANG PERTUMBUHAN
}

\author{
ANGGISTA PUSPITA DEWI \\ ANI WILUJENG SURYANI \\ Jurusan Akuntansi, Fakultas Ekonomi, Universitas Negeri Malang, Jl. Semarang No. 5, Malang, Indonesia \\ ani.suryani@um.ac.id
}

\begin{abstract}
This study aims to determine the influence of asset structure, profitability and growth opportunity on debt policy. Data were collected from 16 Indonesia building construction companies annual reports from 2014 to 2017. The asset structure was measured using fixed assets ratio (FAR), profitability using return on assets (ROA), growth opportunity using price earnings ratio (PER) and debt policy using a debt to equity ratio (DER). The hypothesis was examined using panel data regression analysis. The study showed that debt policy is positively affected by the assest structure, but negatively influenced by profitability. Meanwhile, growth opportunity shows no effect on debt policy. This study implied that companies need to consider increasing profitability in meeting company funds to lower external funding needs. In addition, company managers need to maintain the level of debt to maintain the reputation and trust of external parties to the company and prevent financial distress.
\end{abstract}

Keywords: Debt policy, asset structure, profitability, growth opportunity

Abstrak: Penelitian ini bertujuan untuk mengetahui pengaruh struktur aset, profitabilitas dan peluang pertumbuhan terhadap kebijakan hutang. Data dikumpulkan dari annual report 16 perusahaan konstruksi bangunan di Indonesia selama periode 2014 sampai 2017. Struktur aset diukur dengan menggunakan fixed assets ratio (FAR), profitabilitas menggunakan return on assets $(R O A)$, peluang pertumbuhan menggunakan price earning ratio (PER) dan kebijakan hutang menggunakan debt to equity ratio (DER). Dengan menggunakan analisis regresi data panel, penelitian ini menemukan bahwa kebijakan hutang dipengaruhi secara positif oleh struktur aset, tetapi dipengaruhi secara negatif oleh profitabilitas. Namun, peluang pertumbuhan tidak menunjukkan pengaruh yang signifikan. Hasil penelitian ini dapat menjadi masukan bagi perusahaan perlu mempertimbangkan peningkatan profitabilitas dalam memenuhi dana perusahaan, sehingga kebutuhan dana eksternal tidak tinggi. Selain itu, manajer perusahaan perlu mempertahankan tingkat hutang untuk menjaga reputasi dan kepercayaan pihak eksternal terhadap perusahaan serta mencegah terjadinya financial distress.

Kata kunci: Kebijakan hutang, struktur aset, profitabilitas, peluang pertumbuhan

\section{PENDAHULUAN}

Percepatan pembangunan infrastruktur di era kepemimpinan Presiden Joko Widodo menjadi angin segar bagi perusahaan jasa konstruksi karena menjadi program prioritas pemerintah (Investment, 23 Juni 2017). Hal ini ditunjukkan dengan meningkatnya anggaran belanja negara pada sektor infrastruktur dari Rp 
784,3 triliun di tahun 2005 menjadi Rp 1.375 triliun pada tahun 2015 hingga 2017 dan Rp 410,7 triliun di tahun 2018 (Febrianto 2018, Kemenkeu, 2018; Finance, 2017). Anggaran tersebut digunakan untuk membiayai proyek pembangunan infrasruktur yang dilimpahkan ke perusahaan-perusahaan konstruksi bangunan. Akibatnya, banyak proyek yang harus diselesaikan oleh perusahaan konstruksi sedangkan dana yang tersedia tidak mencukupi karena salah satu sistem pembayarannya yaitu dilakukan setelah proyek selesai (Pasaribu 2006). Oleh karena itu, perusahaan perlu mencari sumber dana eksternal seperti dari hutang.

Penggunaan hutang dipercaya bisa meningkatkan nilai perusahaan karena dianggap memiliki mengalihkan risiko ke kreditor (Indahningrum \& Handayani, 2009). Selain itu, hutang dapat memberikan setidaknya dua manfaat ke perusahaan yaitu bunga yang dibayarkan dapat mengurangi pajak serta pengembalian atas hutang jumlahnya tetap, sehingga tidak mengurangi bagian keuntungan untuk pemegang saham (Brigham \& Houston 2014). Namun, tingginya hutang akan menyebabkan perusahaan mengalami financial distress yang dapat mengarah pada kebangkrutan (Sugeng 2017). Oleh karena itu, perusahaan harus mengoptimalkan kebijakan hutang dengan memperhatikan beberapa hal antara lain struktur aset, profitabilitas dan peluang pertumbuhan (Esperança, Gama, \& Gulamhussen 2003).

Kebijakan hutang yang diambil perusahaan dapat dipengaruhi oleh struktur aset yang merupakan komponen aset, baik aset lancar maupun aset tidak lancar (Syamsuddin 2009). Berdasarkan trade-off theory, perusahaan dapat meningkatkan hutangnya selama masih tersedia jaminan. Ketika perusahaan memiliki proporsi aset tetap lebih dari aset lancar, maka perusahaan cenderung menggunakan hutang (Brigham \& Houston 2014). Hal tersebut dikarenakan aset tetap dapat digunakan sebagai jaminan ke kreditur dalam memberikan hutang kepada perusahaan (Chung 1993). Dengan demikian, perusahaan menganggap bahwa peluang dalam memperoleh hutang akan semakin besar jika aset yang dimiliki semakin banyak, serta asimetri informasi yang terjadi akan semakin kecil (Albaity \& Chuan 2013, Srimindarti \& Hardiningsih 2017).

Faktor lainnya yang berpengaruh terhadap kebijakan hutang yaitu profitabilitas yaitu kemampuan perusahaan dalam menghasilkan laba (Sudana 2015). Menurut pecking order theory, pendanaan internal lebih diutamakan oleh perusahaan. Perusahaan dengan tingkat profitabilitas yang tinggi memiliki tingkat hutang rendah, karena perusahaan mempunyai saldo laba yang mencukupi untuk membiayai operasionalnya (Albaity \& Chuan, 2013; Hoffmann, Bertín, \& Warleta, 2014; Margaretha, 2014). Sebaliknya, apabila profitabilitas rendah, perusahaan akan mempertimbangkan penggunaan hutang untuk membiayai operasionalnya (Myers, 1984).

Faktor ketiga yaitu growth opportunity yang dapat menjadi indikator kinerja perusahaan di masa datang karena memberikan gambaran tentang prospek pertumbuhan di masa mendatang (Brigham \& Houston 2014; Chung, 1993). Tingginya growth opportunity mengindikasikan semakin baik kinerja perusahaan, sehingga kreditur percaya perusahaan dapat membayar kembali hutangnya (Mulyani 2017). Selain itu, peluang 
pertumbuhan juga merupakan tolok ukur untuk menilai tingkat pertumbuhan perusahaan. Tingginya tingkat pertumbuhan mengakibatkan kebutuhan dana yang semakin besar. Perusahaan yang memiliki pertumbuhan pesat cenderung menggunakan sumber dana eksternal dari hutang (Yunita \& Aji 2018). Hal tersebut sesuai dengan trade-off theory dimana perusahaan akan mengoptimalkan penggunaan hutangnya dengan tetap mempertimbangkan kemungkinan terjadinya kebangkrutan (Sugeng 2017).

Penelitian terdahulu yang menguji struktur aset, profitabilitas, maupun peluang pertumbuhan terhadap kebijakan hutang menghasilkan berbagai kesimpulan, sehingga perlu dilakukan penelitian kembali. Penelitian ini berbeda dengan penelitian terdahulu dengan adanya penambahan peluang pertumbuhan.

\section{Struktur Aset}

Struktur aset merupakan proporsi komponen kekayaan perusahaan berupa aset yang terdiri dari aset lancar dan aset tidak lancar (Syamsuddin 2009). Struktur aset merupakan salah satu pertimbangan perusahaan ketika memutuskan untuk berhutang. Jika perusahaan memiliki aset dalam jumlah besar, maka perusahaan bisa memiliki lebih banyak hutang (Brigham \& Houston, 2014). Sesuai dengan trade-off theory, dimana perusahaan dapat meningkatkan hutangnya selama masih tersedia jaminan yang didapat dari aset tetap perusahaan. Apabila aset tetap yang dimiliki ternyata lebih banyak dibanding aset lancar, maka perusahaan akan cenderung menggunakan hutang jangka panjang. Hal ini dikarenakan aset jangka panjang bisa berlaku sebagai jaminan untuk memperoleh pendanaan dari hutang (Tijow et al. 2018). Sebaliknya perusahaan yang mayoritas asetnya berupa aset lancar akan lebih tergantung pada hutang jangka pendek (Weston \& Copeland, 2010). Hal tersebut sesuai dengan penelitian yang telah dilakukan sebelumnya, yaitu struktur aset berpengaruh positif terhadap kebijakan hutang (Akoto \& Awunyo-Vitor 2014; J. J. Chen 2004; Chung, 1993; Esperança et al. 2003; Tijow et al. 2018). Berdasarkan argumen diatas, maka dirumuskan hipotesis sebagai berikut:

$\mathrm{H}_{1}$ : Struktur aset berpengaruh positif signifikan terhadap kebijakan hutang.

\section{Profitabilitas}

Profitabilitas mengukur kemampuan perusahaan dalam memperoleh laba dengan membandingkan ke penjualan, total aset maupun modal sendiri (Brigham \& Houston, 2014). Perusahaan dengan profitabilitas tinggi cenderung menggunakan sebagian dari laba yang diperoleh untuk kegiatan operasional perusahaan (Indahningrum \& Handayani, 2009). Berdasarkan pecking order theory, sumber pendanaan internal lebih utama sehingga adanya laba yang besar mengurangi tingkat pembiayaan eksternal (Brealey, Myers \& Marcus 2008). Perusahaan dengan profitabilitas tinggi akan cenderung untuk menahan labanya, sehingga saldo laba perusahaan semakin besar. Jika perusahaan membutuhkan dana untuk operasional maupun investasi, saldo laba akan digunakan sebagai sumber pendanaan sehingga tingkat hutang relatif rendah, bahkan hingga kemungkinan tidak menggunakan hutang (Albaity \& Chuan 2013, Hoffmann et al. 2014, Margaretha 2014). Oleh karena itu, tinggi rendahnya profitabilitas menentukan rendah tingginya hutang yang dimilikinya. Penjelasan di atas didukung oleh beberapa penelitian yang menyatakan bahwa profitabilitas berpengaruh 
negatif terhadap kebijakan hutang (Desmintari \& Yetty 2014; Gleason et al. 2000; Srimindarti \& Hardiningsih 2017; Tijow et al. 2018). Berdasarkan argumen diatas, maka dirumuskan hipotesis sebagai berikut:

$\mathrm{H}_{2}$ : Profitabilitas berpengaruh negatif signifikan terhadap kebijakan hutang.

\section{Peluang Pertumbuhan}

Peluang pertumbuhan merupakan cerminan dari produktivitas perusahaan dan harapan manajemen, investor dan kreditor. Tingginya tingkat pertumbuhan perusahaan merupakan berita baik karena dapat menumbuhkan kepercayaan pihak eksternal sehingga memberikan kemudahan dalam memperoleh dana, dapat meningkatkan kemampuan perusahaan sehingga dapat berkompetisi di era persaingan bisnis serta peningkatan pangsa pasar (Deesomsak Paudyal, \& Pescetto 2004; Hermuningsih 2013). Penilaian pasar terhadap suatu perusahaan melalui peluang pertumbuhan terlihat dari harga saham yang terbentuk. Investor akan memberikan respon lebih besar kepada perusahaan yang mempunyai peluang pertumbuhan tinggi dibandingkan perusahaan yang growth opportunitynya rendah (Rianawati \& Setiawan 2015). Hal ini disebabkan perusahaan yang memiliki peluang pertumbuhan tinggi diharapkan akan memberikan manfaat yang tinggi bagi investor di masa depan. Selain itu, perusahaan dengan peluang pertumbuhan tinggi akan mengandalkan sumber dana eksternal (Brigham dan Houston 2014; Myers \& Majluf 1984). Berdasarkan trade-off theory, perusahaan dalam masa berkembang sering memerlukan dana yang cukup banyak untuk memperluas usahanya; pemilihan hutang dipilih untuk menghindari tingginya biaya emisi saham, selain itu penggunaan hutang juga dapat digunakan sebagai alat pemacu perusahaan (Yunita \& Aji 2018). Perusahaan dengan high growth opportunity cenderung menjaga hutang mereka pada posisi optimal karena dapat menyebabkan perusahaan menghadapi risiko yang tinggi (Cotei, Farhat, \& Abugri 2011). Penelitian terdahulu juga menunjukkan pengaruh positif peluang pertumbuhan terhadap kebijakan hutang (J. J. Chen 2004; Esperança et al. 2003; Prasetyo et al. 2017; Yunita \& Aji 2018). Berdasarkan argumen diatas, maka dirumuskan hipotesis sebagai berikut:

$\mathrm{H}_{3}$ : Peluang pertumbuhan berpengaruh positif signifikan terhadap kebijakan hutang.

\section{METODE PENELITIAN}

Penelitian ini dilakukan pada perusahaan sub sektor konstruksi bangunan yang terdaftar di BEl pada periode 2014 hingga 2017. Sampel penelitian sebanyak 16 perusahaan dengan 64 laporan keuangan.

Kebijakan hutang diukur menggunakan debt to equity ratio (DER) untuk mengetahui besarnya porsi hutang dibandingkan ekuitas. Oleh karena itu, dapat digunakan untuk melihat apakah modal perusahaan dapat mencukupi untuk membayar pokok dan bunga hutang tersebut (Desmintari \& Yetty 2014; Esperança et al. 2003; Indahningrum \& Handayani 2009; Margaretha \& Asmariani 2009; Mulyani 2017).

$$
\text { DER }=\frac{\text { Total Hutang }}{\text { Total Modal Sendiri }}
$$

Struktur aset yang merupakan proporsi aset tetap yang dimiliki perusahaan 
diukur dengan fixed assets ratio (FAR). FAR dapat dijadikan sebagai jaminan hutang serta menegaskan keberadaan sumber daya yang cukup untuk mendapatkan hutang dari kreditor (Akoto \& Awunyo-Vitor 2014; J. J. Chen, 2004; Esperança et al. 2003; Tijow et al. 2018).

$$
\mathrm{FAR}=\frac{\text { Aset Tetap }}{\text { Total Aset }}
$$

Profitabilitas yang merupakan kemampuan perusahaan dalam menghasilkan laba diukur dengan return on assets (ROA). ROA digunakan untuk mengukur kemampuan perusahaan untuk menghasilkan laba dengan memanfaatkan aset yang dimiliki perusahaan (Akoto \& Awunyo-Vitor 2014; J. J. Chen, Jiang, \& Lin 2014; Desmintari \& Yetty 2014; Haron, 2016; Margaretha 2014).

$$
\text { ROA }=\frac{\text { Laba Bersih }}{\text { Total Aset }}
$$

Peluang pertumbuhan menunjukan peluang perusahaan dalam melakukan pertumbuhan di masa depan, diukur menggunakan price earning ratio (PER). PER digunakan karena dapat menunjukkan bagaimana kondisi perusahaan saat itu. Ketika harga saham perusahaan tinggi maka banyak investor yang tertarik sehingga menunjukkan kondisi keuangan perusahaan yang baik (Chung 1993; Goyal et al, 2002).

$$
\begin{aligned}
& \text { PER } \\
& =\frac{\text { harga penutupan per lb saham }}{\text { earning per share }}
\end{aligned}
$$

Dalam pengujian hipotesis dipertimbangkan adanya variabel kontrol untuk menguji struktur aset, profitabilitas dan peluang pertumbuhan yaitu ukuran perusahaan dan umur perusahaan (Alnajjar \& Belkaoui 2001; Goyal et al. 2002; Margaretha \& Asmariani 2009). Ukuran perusahaan diukur dengan menggunakan rumus:

$$
\text { Size }=\operatorname{Ln}(\text { Total Aset })
$$

Umur perusahaan dihitung sejak berdirinya perusahaant akta pendirian sampai tahun penelitian. Teknik analisis data yang digunakan dalam penelitian ini adalah analisis regresi panel. Analisis regresi panel digunakan untuk mengetahui pengaruh struktur aset, profitabilitas dan peluang pertumbuhan terhadap kebijakan hutang. Dalam regresi panel terdapat tiga pilihan model estimasi yang diperlukan yaitu common effect, fixed effect, dan random effect. Sebelum melakukan analisis regresi panel dilakukan, maka diperlukan uji asumsi klasik terdahulu yaitu uji normalitas, uji multikolinearitas dan uji heteroskedastisitas.

\section{HASIL PENELITIAN}

Tabel 1 menunjukkan nilai mean dari kebijakan hutang sebesar $126,96 \%$. Hal ini berarti rata-rata perusahaan konstruksi bangunan di Indonesia lebih banyak menggunakan hutang dibanding modal sendiri. Hutang yang tinggi menyebabkan beban yang ditanggung perusahaan lebih tinggi sehingga berdampak pada berkurangnya laba yang dihasilkan (Wardhana 2013). Selain itu, nilai minimum kebijakan hutang sebesar 0,77\% terjadi pada perusahaan Totalindo Eka Persada Tbk (TOPS). Hal tersebut dikarenakan TOPS memiliki profitabilitas yang lebih tinggi yaitu sebesar 5\% sehingga laba yang mereka hasilkan dapat menutupi biaya operasionalnya.

Nilai mean dari struktur aset sebesar 9,54\% menunjukkan rata-rata perusahaan konstruksi bangunan lebih mengandalkan aset lancar daripada aset tetap. Perusahaan konstruksi bangunan dengan banyak proyek akan menghasilkan piutang usaha yang tinggi, sehingga tingkat aset lancar akan lebih banyak dibanding aset tetap. Piutang tersebut mudah didapatkan oleh perusahaan ketika proyek yang 
dikerjakan telah selesai, sehingga piutang usaha dapat digunakan kapanpun.

Nilai mean dari profitabilitas sebesar $5,22 \%$ yang berarti bahwa rata-rata perusahaan konstruksi bangunan di Indonesia dalam memanfaatkan asetnya untuk menghasilkan laba cukup rendah. Hal ini menunjukkan bahwa perusahaan konstruksi bangunan dianggap tidak sehat dalam menghasilkan laba karena berada dibawah standar rasio profitabilitas sebesar 30\% (Kasmir 2015).

Peluang pertumbuhan memiliki nilai minimum $-0,78 \%$, menunjukkan bahwa terdapat perusahaan yang tidak mampu mengembangkan usahanya, yaitu terjadi pada
PT Nusa Konstruksi Enjiniring karena pada tahun 2016 perusahaan tersebut sempat mengalami kerugian. Ukuran perusahaan memiliki nilai mean sebesar 29,30 . Nilai tersebut mengindikasikan bahwa ukuran perusahaan konstruksi bangunan tergolong sedang, dengan nilai standar deviasi 1,43 yang berarti bahwa tidak terdapat perbedaan yang cukup besar antar perusahaan (Japlani, 2015). Umur perusahaan memiliki nilai mean sebesar 42,59 yang menunjukkan bahwa rata-rata umur perusahaan konstruksi bangunan yang cukup tua karena perusahaan yang telah lama berdiri memiliki pengalaman yang lebih baik dibanding dengan perusahaan baru.

Tabel 1 Statistik Deskriptif

\begin{tabular}{lrrrr}
\hline \multicolumn{1}{c}{ Variabel } & Minimum & \multicolumn{1}{c}{ Maximum } & \multicolumn{1}{c}{ Mean } & \multicolumn{1}{c}{ Std. Deviation } \\
\hline Y Keb Hutang & 0.77 & 274.00 & 126.96 & 76.73 \\
X $_{1}$ Struktur Aset & 4.14 & 16.81 & 9.54 & 3.30 \\
X $_{2}$ Profit & 2.44 & 9.81 & 5.22 & 1.61 \\
X $_{3}$ Growth Opp & -0.78 & 36.73 & 16.51 & 8.22 \\
Z $_{1}$ Size & 26.28 & 32.21 & 29.30 & 1.43 \\
Z $_{2}$ Age & 9.00 & 64.00 & 42.59 & 14.14 \\
\hline
\end{tabular}

Analisis korelasi bertujuan untuk mengetahui hubungan antara variabel. Tabel 2 menunjukkan hasil analisis korelasi dengan menggunakan analisis pearson. Hasil analisis menunjukkan bahwa struktur aset dan peluang pertumbuhan berkorelasi positif signifikan dengan kebijakan hutang, sedangkan profitabilitas berkorelasi negatif signifikan. Keseluruhan variabel kontrol berkorelasi positif dengan kebijakan hutang.

Tabel 2 Hasil Analisis Korelasi

\begin{tabular}{|c|c|c|c|c|c|c|c|}
\hline & & 1 & 2 & 3 & 4 & 5 & 6 \\
\hline 1 & Keb Hutang & 1.000 & & & & & \\
\hline 2 & Struktur Aset & $0.546^{* *}$ & 1.000 & & & & \\
\hline 3 & Profit & $-0.591^{* \star *}$ & $-0.368^{*}$ & 1.000 & & & \\
\hline 4 & Growth Opp & $0.625^{* *}$ & $0.488^{\star \star *}$ & $-0.504^{* * *}$ & 1.000 & & \\
\hline 5 & Size & $0.363^{*}$ & 0.153 & -0.146 & 0.232 & 1.000 & \\
\hline 6 & Age & $0.428^{* \star}$ & 0.223 & -0.218 & $0.304^{*}$ & $0.721^{* * *}$ & 1.000 \\
\hline
\end{tabular}


Catatan: korelasi *signifikan pada $p<0.05,{ }^{* *} p<0.01,{ }^{* * *} p<0.001$.

Tabel 3 menunjukkan hasil uji untuk pemilihan model regresi yang paling tepat. Hasil dari $L M$ test menunjukkan bahwa kedua model memiliki $p$-value $>0,05$ sehingga estimasi yang lebih baik digunakan yaitu common effect. Selanjutnya, karena estimasi yang terpilih yaitu common effect, maka dilakukan chow test. Chow test menunjukkan hasil bahwa dari model
1 maupun model 2 menghasilkan $p$-value $<0,05$, sehingga estimasi yang lebih baik digunakan yaitu fixed effect. Pengujian terakhir yaitu hausman test yang memiliki hasil $p$-value $>0,05$, sehingga estimasi yang lebih tepat digunakan yaitu random effect.

Tabel 3 Pemilihan Model Estimasi Panel

\begin{tabular}{lcc}
\hline Uji Model Regresi & Model 1 (tanpa variabel kontrol) & Model 2 (dengan variabel kontrol) \\
\hline LM test & 0,1116 & 0,43017 \\
Chow Test & 0,0000 & 0,0003 \\
Hausman Test & 0,0891 & 0,3094 \\
\hline
\end{tabular}

Model regresi yang tepat dalam penelitian ini yaitu random effect. Berdasarkan Tabel 4, ketika $X_{1}$ (Struktur Aset), $X_{2}$ (Profitabilitas) dan $X_{3}$ (Peluang Pertumbuhan) masing-masing bernilai 0 maka nilai kebijakan hutang tetap sebesar 0,642. Apabila ada peningkatan $1 \%$ pada nilai struktur aset maka kebijakan hutang akan naik $8,89 \%$ dengan asumsi variabel lainnya sama. Namun, apabila nilai profitabilitas meningkat $1 \%$ maka kebijakan hutang akan turun $-12.07 \%$. Terdapat perbedaan antara model 1 (tanpa variabel kontrol) dengan model 2 (dengan variabel kontrol) yaitu perubahan pada nilai konstanta yang semula bernilai positif $(0,642)$ menjadi negatif $(-0,993)$. Hal ini mungkin dikarenakan variabel kontrol ukuran perusahaan memiliki perbedaan nilai yang cukup besar dengan nilai tertinggi mencapai 97 triliun dan nilai terendah sebesar 259 miliar. Namun, perubahan dari nilai konstanya yang menjadi negatif tidak memengaruhi hasil persamaan regresi karena uji asumsi klasik telah terpenuhi, nilai slope $(\beta)$ tidak bernilai 0 , serta konstanta tidak signifikan (Jondeau \& Rockinger, 2003).

Tabel 4 menunjukkan bahwa nilai uji $F$ kurang dari 0,05 sehingga model dapat fit dengna data. Kemudian, $R$-Square memiliki nilai 0.465 yang berarti struktur aset, profitabilitas dan peluang pertumbuhan mampu menjelaskan $46,5 \%$ variasi dari kebijakan hutang. 
Tabel 4 Hasil regresi

\begin{tabular}{lcc}
\hline \multicolumn{1}{c}{ Variabel } & Model I & Model II \\
\hline (Constan) & 0.642 & -0.993 \\
X $_{1}$ Struktur Aset & $8.892^{* *}$ & $8.104^{*}$ \\
X $_{2}$ Profit & $-12.070^{*}$ & $-11.809^{*}$ \\
X $_{3}$ Growth Opp & $0.019^{+}$ & 0.018 \\
Z $_{1}$ Size & & 0.044 \\
Z $_{2}$ Age & & 0.011 \\
$\mathrm{R}^{2}$ & 0.465 & 0.501 \\
Sig. Uji F & 0.000 & 0.000 \\
\hline
\end{tabular}

Catatan: koefisien regresi ${ }^{*}$ signifikan pada $p<0.05,{ }^{* *} p<0.01,{ }^{* * *} p<0.001$.

Tabel 5 menunjukkan bahwa bahwa $\mathrm{X}_{1}$ memiliki nilai $p$-value $<0,05$ yang berarti struktur aset berpengaruh positif signifikan terhadap kebijakan hutang. Hal tersebut berarti $\mathrm{H}_{1}$ yang menyatakan bahwa struktur aset berpengaruh positif signifikan tidak dapat ditolak. Variabel $X_{2}$ memiliki nilai $p$-value $<0,05$ dan koefisien bertanda negatif (-) yang berarti profitabilitas berpengaruh negatif signifikan terhadap kebijakan hutang.
Dengan demikian, $\mathrm{H}_{2}$ yang menyatakan profitabilitas berpengaruh negatif signifikan tidak dapat ditolak. Variabel $X_{3}$ memiliki nilai $p$-value $>0,05$ dan koefisien bertanda positif $(+)$ yang berarti peluang pertumbuhan tidak berpengaruh terhadap kebijakan hutang. Dengan demikian, $\mathrm{H}_{3}$ yang menyatakan peluang pertumbuhan berpengaruh positif signifikan ditolak.

Tabel 5 Hasil Uji t

\begin{tabular}{lcccc}
\hline & Coefficient & Std. Error & t-Statistic & Prob. \\
\hline Model 1 & & & & \\
(Constant) & 0.642 & 0.489 & 1.313 & 0.197 \\
X $_{1}$ Struktur Aset & 8.892 & 2.893 & 3.074 & 0.004 \\
X $_{2}$ Profit & -12.070 & 5.236 & -2.305 & 0.026 \\
X $_{3}$ Growth Opp & 0.019 & 0.010 & 1.849 & 0.072 \\
Model 2 & & & & \\
(Constant) & -0.993 & 1.948 & -0.510 & 0.613 \\
X $_{1}$ Struktur Aset & 8.104 & 3.012 & 2.690 & 0.011 \\
X $_{2}$ Profit & -11.809 & 5.819 & -2.029 & 0.050 \\
X $_{3}$ Growth Opp & 0.018 & 0.011 & 1.580 & 0.123 \\
Z $_{1}$ Size & 0.044 & 0.068 & 0.655 & 0.517 \\
Z $_{2}$ Age & 0.011 & 0.008 & 1.446 & 0.157 \\
\hline
\end{tabular}

Hasil penelitian ini menemukan bahwa struktur aset berpengaruh positif signifikan terhadap kebijakan hutang yang berarti semakin tinggi aset tetap yang dimiliki perusahaan, maka semakin besar tingkat hutang perusahaan dan sebaliknya, semakin rendah struktur aset maka 
semakin rendah kebijakan hutangnya. Besarnya aset tetap mengimplikasikan tinggnya jaminan untuk hutang, sehingga perusahaan akan mudah untuk meningkatkan hutangnya (Tijow et al., 2018). Dengan besarnya jaminan yang dapat diberikan, maka kreditur akan memberikan kepercayaan yang membuat perusahaan semakin mudah dalam memperoleh hutang. Selain itu, tingginya aset tetap mengindikasikan rendahnya risiko kebangkrutan (Dewi \& Dana, 2017). Hasil penelitian ini mendukung penelitian terdahulu yang dilakukan oleh Akoto \& AwunyoVitor (2014), Chung (1993), Esperança et al. (2003) dan Tijow et al. (2018) yang memiliki kesamaan dalam hal proxy perhitungan struktur aset. Hal tersebut mengindikasikan bahwa tingginya struktur aset di perusahaan konstruksi bangunan di Indonesia akan berpengaruh pada tingginya hutang perusahaan. Hal tersebut sesuai dengan analisis korelasi bahwa terdapat korelasi antara struktur aset dengan kebijakan hutang.

Hasil regresi menunjukkan bahwa struktur aset memiliki pengaruh sebesar 8,8\% terhadap kebijakan hutang. Hal ini berarti struktur aset dalam perusahaan konstruksi bangunan didominasi oleh aset lancar dibanding aset tetap. Dilihat dari 16 perusahaan yang diteliti, sebagian besar perusahaan lebih banyak memiliki aset lancar dibanding aset tetapnya. Ketika aset lancar lebih banyak, maka kemungkinan menandakan bahwa perusahaan dalam keadaan tidak sehat. Misalnya, ketika kas perusahaan terlalu tinggi dapat menunjukkan bahwa perusahaan tidak memutar dananya yang berarti tingkat investasi rendah. Hasil penelitian ini sesuai dengan trade-off theory yang menyatakan bahwa perusahaan masih dapat menambah hutang selama masih terdapat kaminan berupa aset tetap (Tijow et al. 2018).
Akan tetapi, perusahaan harus tetap berhati-hati dalam menggunakan hutang dengan memperhatikan besarnya bunga yang harus dibayar agar tidak terjadi kerugian. Dengan demikian dapat disimpulkan bahwa perusahaan dengan struktur aset tinggi dapat meningkatkan tingkat hutangnya karena aset yang dimiliki dapat dijadikan sebagai jaminan. Selain itu, struktur aset dapat memberikan keyakinan kepada kreditur.

Profitabilitas berpengaruh negatif signifikan terhadap kebijakan hutang. Hasil ini mengindikasikan bahwa perusahaan konstruksi bangunan di Indonesia mempertimbangkan profitabilitas dalam menentukan kebijakan hutangnya. Hasil penelitian ini mendukung penelitian terdahulu yang dilakukan oleh J. J. Chen (2004), Gleason et al. (2000), Srimindarti \& Hardiningsih (2017), Tijow et al. (2018). Tinggi rendahnya tingkat profitabilitas mempengaruhi rendah tingginya tingkat hutang (Albaity \& Chuan 2013; Hoffmann et al. 2014; Yuniarti 2013). Hasil dari regresi juga menunjukkan bahwa profitabilitas mempengaruhi kebijakan hutang hanya sebesar $12,07 \%$. Hal tersebut berarti perusahaan belum mampu memanfaatkan aset yang dimiliki dengan baik untuk menghasilkan laba. Tingginya aset yang tidak diimbangi dengan perolehan laba yang tinggi bisa menyebabkan rendahnya tingkat profitabilitas. Rendahnya profitabilitas menyebabkan penggunaan hutang yang tinggi. Hasil penelitian ini sesuai dengan pecking order theory yang menyatakan bahwa terdapat klasifikasi pendanaan yang digunakan perusahaan (Myers 1984). Perusahaan lebih menyukai laba yang diperoleh untuk mendanai operasionalnya. Penggunaan sumber dana eksternal hanya akan dilakukan ketika pendanaan internal perusahaan tidak 
mencukupi, dengan memilih pendanaan hutang. Sesuai dengan hasil penelitian yang dilakukan, perusahaan konstruksi bangunan di Indonesia lebih menggunakan pilihan sumber dana kedua yaitu hutang. Hutang memiliki biaya yang lebih sedikit dibandingkan saham. Akan tetapi, pembiayaan dengan hutang membuat beban bunga yang ditanggung tetap, terlepas dari bagaimana kinerja perusahaan tersebut (Albaity \& Chuan 2013).

Penelitian ini tidak dapat menunjukkan bahwa peluang pertumbuhan berpengaruh terhadap kebijakan hutang. Penelitian ini tidak sejalan dengan J. J. Chen, (2004), Esperança et al. (2003), Prasetyo et al. (2017). Hal ini mengindikasikan bahwa tinggi rendahnya peluang pertumbuhan perusahaan tidak mempengaruhi kebijakan hutang yang akan diambil. Hasil ini tidak mendukung trade-off theory dimana perusahaan dengan pertumbuhan yang tinggi akan tergantung pada dana eksternal yaitu hutang (Ghazouani, 2013). Hutang dipilih untuk menghindari biaya emisi saham yang tinggi. Akibatnya, perusahaan dengan pertumbuhan yang tinggi akan memiliki hutang lebih tinggi daripada perusahaan dengan pertumbuhan rendah. Oleh karena itu, perusahaan akan cenderung menggunakan saldo laba daripada hutang untuk menghindari risiko gagal bayar kredit (Sheikh \& Wang, 2011). Selain itu, penggunaan saldo laba juga diakibatkan tingginya laba yang diperoleh perusahaan sehingga pembiayaan operasional berasal dari laba yang diperoleh sebelumnya. Namun, model trade-off tidak berlaku untuk perusahaan Indonesia. Salah satu alasannya mungkin karena perusahaan yang terdaftar di sektor konstruksi bangunan mengalami penurunan nilai saham yang beredar sebesar $2,88 \%$. Hal tersebut dapat menunjukkan bahwa perusahaan konstruksi bangunan di Indonesia mengalami masa krisis karena kurangnya kepercayaan investor terhadap perusahaan (Kontan 2017). Kemungkinan lain yang menyebabkan peluang pertumbuhan tidak berpengaruh dengan kebijakan hutang karena rasio PER yang dijadikan sebagai alat ukur variabel ini merupakan rasio dari ekuitas perusahaan (Sheikh \& Wang 2011). Harga saham dan EPS yang berfluktuatif tidak memiliki kepastian untuk dapat meyakinkan kreditur. Oleh karena itu, baik tinggi rendahnya peluang pertumbuhan yang dicapai, tidak mempengaruhi hutang perusahaan.

\section{PENUTUP}

Penelitian ini berfokus pada pengaruh struktur aset, profitabilitas dan peluang pertumbuhan terhadap kebijakan hutang pada perusahaan konstruksi tahun 2014 hingga 2017. Berdasarkan pengujian yang telah dilakukan, maka terdapat tiga kesimpulan. Pertama, struktur aset berpengaruh positif signifikan terhadap kebijakan hutang. Hasil ini konsisten dengan penelitian sebelumnya dimana proporsi aset perusahaan yang tinggi akan meningkatkan penggunaan hutangnya. Selain itu, hasil ini juga sesuai dengan trade-off theory yaitu masih dapat melakukan penambahan hutang selama masih terdapat aset tetap sebagai jaminan. Dengan demikian, besarnya aset tetap yang dimiliki perusahaan menentukan tingginya penggunaan hutang perusahaan. Oleh karena itu, perusahaan perlu mempertimbangkan seberapa besar struktur aset yang harus dimiliki agar dana yang dibutuhkan dapat terpenuhi. Selanjutnya, bagi kreditur yang akan meminjamkan dananya kepada perusahaan, perlu melihat struktur aset yang dimiliki perusahaan sebagai bahan pertimbangan kelayakan perusahaan untuk memperoleh hutang. 
Kedua, profitabilitas berpengaruh negatif terhadap kebijakan hutang. Penelitian ini konsisten dengan penelitian terdahulu yang menemukan bahwa perusahaan dengan profitabilitas tinggi akan cenderung memiliki hutang rendah dan sebaliknya, profitabilitas yang rendah akan memiliki hutang tinggi. Hasil ini juga sesuai dengan pecking order theory, perusahaan menggunakan pilihan sumber dana kedua yaitu hutang karena profitabilitas yang dimiliki rendah. Rendahnya profitabilitas disebabkan oleh rendahnya kemampuan manajer dalam mengelola asetnya, sehingga kurang mampu menghasilkan laba. Hal tersebut dapat menjadi pertimbangan bagi manajemen perusahaan agar dapat meningkatkan kemampuan dalam mengelola aset agar memperoleh laba yang memuaskan, sehingga dana yang diperlukan tercukupi. Bagi kreditur, profitabilitas perusahaan dapat menjadi pertimbangannya karena profitabilitas tinggi menggambarkan kemampuan perusahaan menghasilkan laba dengan baik, sehingga perusahaan dinilai mampu untuk membayar pokok dan bunga hutang.

Ketiga, hasil penelitian menemukan bahwa peluang pertumbuhan tidak berpengaruh dengan kebijakan hutang. Hal tersebut mungkin dikarenakan perusahaan lebih memilih saldo laba untuk mendanai operasionalnya. Kemungkinan lain disebabkan saham yang beredar mengalami penurunan nilai, sehingga menyebabkan kurangnya kepercayaan investor terhadap perusahaan. Selanjutnya, komponen dari rasio PER yang berfluktuatif adanya kepastian untuk dapat meyakinkan kreditur. Oleh karena itu, baik tinggi maupun rendah peluang pertumbuhan yang dicapai perusahaan, tidak akan mempengaruhi penggunaan hutangnya. Selain itu, penelitian ini tidak mendukung trade-off theory yang menjelaskan bahwa perusahaan yang dalam masa growth membutuhkan dana yang lebih banyak untuk membiayai operasionalnya. Bagi investor yang ingin menanamkan dananya kepada perusahaan, perlu memperhatikan bagaimana peluang di masa depan perusahaan sebelum mengambil keputusan agar investor tidak mengalami kerugian.

Keterbatasan dalam penelitian ini adalah penggunaan pengukuran PER dalam mengukur peluang pertumbuhan. Hal ini dikarenakan pendapatan yang dihasilkan perusahaan didasarkan pada accrual basis yang dapat dinaikkan atau diturunkan sesuai dengan keinginan perusahaan, sehingga tidak dapat menggambarkan kondisi finansial perusahaan yang sebenarnya. Oleh karena itu, penelitian selanjutnya dapat dilakukan dengan menggunakan pengukuran lain seperti asset growth. Selain itu, penelitian selanjutnya dapat menambahkan variabel lain yang mungkin berpengaruh terhadap kebijakan hutang, seperti earning volatility. 


\section{REFERENCES:}

Akoto, R. K., \& Awunyo-Vitor, D. 2014. What Determines the Debt Policy of Listed Manufacturing Firms in Ghana? International Business Research, 7(1), 42-48. https://doi.org/10.5539/ibr.v7n1p42

Albaity, M. S., \& Chuan, A. H. S. 2013. Internationalization and Capital Structure: Evidence from Malaysian Manufacturing Firms. Asian Journal of Finance \& Accounting, 5(2), 329-342. https://doi.org/10.5296/ajfa.v5i2.4533

Alnajjar, F. K., \& Belkaoui, A. R. 2001. Empirical Validation of a General Model of Growth Opportunities. Managerial Finance, 27(3), 72-90.

Atmaja, Lukas Setia. 2008. Teori dan Praktek Manajemen Keuangan. Yogyakarta: Andi.

Brealey, Richard A., Myers, Steward C., \& Marcus, Alan J. 2008. Dasar-Dasar Manajemen Keuangan Perusaahaan Jilid 2. Terjemahan Bob Sabran. Jakarta: Erlangga.

Brigham, Eugene F., \& Houston, Joel F. 2014. Dasar-Dasar Manajemen Keuangan Buku 2. Terjemahan Ali Akbar Yuliantor. Jakarta: Salemba Empat

Chen, J. J. 2004. Determinants of capital structure of Chinese-listed companies. Journal of Business Research, 57(12 SPEC.ISS.), 1341-1351. https://doi.org/10.1016/S0148-2963(03)00070-5

Chen, J., Jiang, C., \& Lin, Y. 2014. What determine firms' capital structure in China? Managerial Finance, 40(10), 1024-1039. https://doi.org/10.1108/MF-06-2013-0163

Chung, K. H. 1993. Asset Characteristic and Corporate Debt Policy: an Empirical Test. Journal of Business Finance \& Accounting, 20(1), 83-98. Retrieved from http:/lescweb.lib.cbs.dk/login?url=http://search.ebscohost.com/login.aspx?direct=true\&db=bth\&AN=5824760\&site=e host-live\&scope=site

Cotei, C., Farhat, J., \& Abugri, B. A. 2011. Testing trade-off and pecking order models of capital structure: does legal system matter? Managerial Finance, 37(8), 715-735. https://doi.org/10.1108/03074351111146193

Deesomsak, R., Paudyal, K., \& Pescetto, G. 2004. The determinants of capital structure: Evidence from the Asia Pacific region. Journal of Multinational Financial Management, 14(4-5), 387-405. https://doi.org/10.1016/j.mulfin.2004.03.001

Desmintari, \& Yetty, F. 2014. Effect of Profitability, Liquidity and Assets Structure on the Company Debt Policy. International Journal of Business and Commerce, 5(06), 117-131.

Dewi, N. K. T. S., \& Dana, I. M. 2017. Pengaruh Growth Opportunity, Likuiditas, Non-Debt Tax Shield dan Fixed Asset Ratio terhadap Struktur Modal. E-Jurnal Manajemen Unud, 6(2), 772-801.

Dwilestari, A. (2010). Pengaruh Struktur Aktiva, Pertumbuhan, dan Likuiditas Terhadap Struktur Modal Perusahaan. Jurnal Riset Akuntansi Dan Keuangan, 6(2), 153-165.

Ekananda, M. 2015. Ekonometrika Dasar Untuk Penelitian Ekonomi, Sosial dan Bisnis. Jakarta: Mitra Wacana Media.

Esperança, J. P., Gama, A. P. M., \& Gulamhussen, M. A. 2003. Corporate debt policy of small firms: An empirical (re)examination. Journal of Small Business and Enterprise Development, 10(1), 62-80. https://doi.org/10.1108/14626000310461213

Fahmi, Irham. 2014. Manajemen Keuangan Perusahaan dan Pasar Modal. Jakarta: Mitra Wacana Media.

Febrianto, Heru. 2018. Emiten Konstruksi BUMN Berpeluang Naik. (online), (https://economy.okezone.com/read/2018/03/14/278/1872463/emiten-konstruksi-bumn-berpeluang-naik), diakses 5 September 2018.

Finance, Detik. 2017. Saham Konstruksi Terimbas Pembangunan Infrastruktur. (online), (https://finance.detik.com/market-research/d-3434777/saham-konstruksi-terimbas-pembangunaninfrastruktur), diakses 02 September 2018.

Gaud, P., Jani, E., Hoesli, M., \& Bender, A. 2005. The Capital Structure of Thai Companies : Empirical Analysis 
Using Dynamic Panel Data . The Capital Structure of Thai Companies : Empirical Analysis Using Dynamic Panel Data . European Financial Management, 11(1), 51-69.

Ghazouani, T. 2013. The Capital Structure through the Trade-Off Theory: Evidence from Tunisian Firm. International Journal of Economics and Financial Issues, 3(3), 625-636.

Gleason, K. C., Mathur, L. K., \& Mathur, I. 2000. The Interrelationship Between Culture, Capital Structure, and Performance: Evidence From European Retailers. Journal of Business Finance \& Accounting, 50(01482963), 185-191.

Goyal, V. K., Lehn, K., \& Racic, S. 2002. Growth opportunities and corporate debt policy: the case of the U . S . defense industry. Journal of Financial Economics, 64, 35-59.

Hanafi, Mamduh M., \& Halim, Abdul. 2016. Analisis Laporan Keuangan. Yogyakarta: UPP STIM YKPN.

Hardiningsih, P., \& Oktaviani, R. M. 2012. Determinan kebijakan hutang (dalam agency theory dan pecking order theory). Dinamika Akuntansi, Keuangan Dan Perbankan Universitas Stikubank, 1(1), 11-24.

Haron, R. 2016. Do Indonesian Firms Practice Target Capital Structure? A Dynamic Approach. Journal of Asia Business Studies, 10(3). https://doi.org/10.1108/LHT-10-2015-0096

Hermuningsih, S. 2013. Pengaruh Profabilitas, Growth Opportunity, Struktur Modal Terhadap Nilai Perusahaan Pada Perusahaan Publikdi Indonesia. Buletin Ekonomi Moneter Dan Perbankan.

Hoffmann, P. S., Bertín, M. J., \& Warleta, M. M. 2014. Firm Size as Determinant of the Nonlinear Relationship Between Bank Debt and Growth Opportunities: The Case of Chilean Public Firms. Emerging Markets Finance and Trade, 50(s1), 265-293. https://doi.org/10.2753/REE1540-496X5001S117

Indahningrum, R. P., \& Handayani, R. 2009. Pengaruh Kepemilikan Manajerial, Kepemilikan Institusional, Dividen, Pertumbuhan Perusahaan, Free Cash Flow, dan Profitabilitas Terhadap Kebijakan Hutang Perusahaan. Jurnal Bisnis Dan Akuntansi, 11(3), 189-207.

Investment. 2017. Infrastruktur di Indonesia. (online), (https://www.indonesiainvestments.com/id/bisnis/risiko/infrastruktur/item381?), diakses 02 September 2018.

Japlani, A. 2015. Apakah ukuran itu penting? Akuisisi, 11(1), 1-21.

Jondeau, E., \& Rockinger, M. 2003. Conditional Volatility, Skewness, and Kurtosis: Existence, Persistence, and Comovements. Journal of Economic Dynamics \& Control, 27, 1699-1737.

Kasmir. 2015. Analisis Laporan Keuangan. Jakarta: Rajawali Press.

Kemenkeu, 2018. APBN 2018. (online), (https://www.kemenkeu.go.id/apbn2018), diakses 4 September 2018.

Kontan (a). 2017. Saham Property \& Konstruksi Berpotensi Outperform. (online), (https://investasi.kontan.co.id/news/saham-properti-konstruksi-berpotensi-outperform), diakses 6 Maret 2019.

Kontan (b). 2018. Investor Perlu Perhatikan Saham Emiten dengan Kinerja Mencemaskan Sepanjang 2016-2018. (online), (https://investasi.kontan.co.id/news/investor-perlu-perhatikan-saham-emiten-dengan-kinerjamencemaskan-sepanjang-2016-2018), diakses 8 Mei 2019.

Manoppo, M., Mangantar, M., \& Rate, P. Van. 2018. Pengaruh Struktur Aset Terhadap Kebijakan Hutang Pada Perusahaan Otomotif Yang Terdaftar Di BEI Periode 2012-2016. Jurnal EMBA, 6(3), 1788-1797.

Margaretha, F. 2014. Determinants of Debt Policy in Indonesia 's Public Company, 3(2), 10-16.

Margaretha, F., \& Asmariani, A. 2009. Faktor Faktor Agency Theory Yang Mempengaruhi Hutang. Media Riset Bisnis \& Manajemen, 9(1), 1-20.

Mulyani, H. S. 2017. Analisis Struktur Modal Berdasarkan Growth Opportunity, Profitabilitas, Effektive Tax Rate Dan Asset Tangibility. Jurnal IImiah Manajemen \& Akuntansi, 4(2). Retrieved from http://jurnal.unma.ac.id/index.php/mk/article/download/735/685

Myers, S. C. 1984. The Capital Structure Puzzle. The Journal of Finance, 39(3), 575-592.

Myers, S. C., \& Majluf, N. S. 1984. Corporate financing and investment decisions when firms have information that investors do not have.pdf. Journal of Financial Economics, 13, 187-221. https://doi.org/10.1016/0304- 
405X(84)90023-0

Narita, R. M. 2012. Analisis Kebijakan Hutang. Accounting Analysis Journal, 1(2), 378-386.

Pasaribu, Chandra Sahala. 2006. Konstruksi dan Infrastruktur. (online), (http://perpustakaan.bappenas.go.id//ontar/file?file=digital/blob/F27516/Konstruksi\%20dan\%20Infrastruktur. $\mathrm{htm}$ ), diakses 02 September 2018.

Prasetyo, F. E., Swandari, D. F., \& Dewi, D. D. M. 2017. Pengaruh Profitabilitas, Pajak dan Growth Opportunity Terhadap Nilai Perusahaan Melalui Struktur Modal Sebagai Variabel Intervening. Jurnal Wawasan Manajemen, 5(i), 51-62.

Prathiwi, N. M. D. I., \& Yadnya, I. P. 2017. Pengaruh Free Cash Flow, Struktur Aset, Risiko Bisnis Dan Profitabilitas Terhadap Kebijakan Hutang. E-Junal Manajamen Unud, 6(1), 60-86.

Rianawati, A., \& Setiawan, R. 2015. Leverage, Growth Opportunity, Dan Investasi Pada Perusahaan Non Keuangan Yang Terdafar di BEl. Jurnal Manajemen Dan Terapan, 8(1).

Saputro, R. C., \& Yuliandhari, W. S. 2015. Pengaruh Struktur Aktiva, Profitabilitas dan Kebijakan Dividen Terhadap Kebijakan Hutang. E-Proceeding of Management, 2(3), 3084-3091.

Sheikh, N. A., \& Wang, Z. 2011. Determinants of Capital Structure: An Empirical Study of Firms in Manufacturing Industry of Pakistan. Managerial Finance, 37(2), 117-133. https://doi.org/10.1108/03074351111103668

Srimindarti, C., \& Hardiningsih, P. 2017. Pengaruh Struktur Asset Perusahaan Terhadap Struktur Modal Dimoderasi Profitabilitas. Jurnal Bingkai Manajemen Seminar Nasioal Dan Call for Paper, (20), 348-360.

Sudana, I Made. 2015. Manajemen Keuangan Perusahaan. Jakarta: Erlangga.

Sugeng, Bambang. 2017. Manajemen Keuagan Fundamental. Yogyakarta: Deepublish.

Syamsuddin, Lukman. 2009. Manajemen Keuangan Perusahaan: Konsep Aplikasi dalam Perencanaan, Pengawasan, dan Pengambilan Keputusan. Jakarta: Rajawali Pers.

Tijow, A. P., Sabijono, H., \& Tirayoh, V. Z. 2018. Pengaruh Struktur Aktiva Dan Profitabilitas Terhadap Struktur Modal Pada Perusahaan Sektor Industri Barang Konsumsi Yang Terdaftar Di Bursa Efek Indonesia. Jurnal Riset Akuntansi Going Concern, 13(3), 477-488. Retrieved from https://ejournal.unsrat.ac.id/index.php/gc/article/view/20375

Wardhana, G. H. 2013. Pengaruh Profitability, Asset Tangibility dan Institutional Ownership terhadap Struktur Modal dan Dampaknya pada Kebijakan Dividen. Jurnal Bisnis Strategi, 21(1), 95-111.

Weston, J. Fred., \& Copeland, Thomas E. 2010. Manajemen Keuangan Edisi Revisi Jilid 2. Terjemahan A. Jaka Wasana, Kibrandoko. Tangerang: Binarupa Aksara.

Winarno, Wing Wahyu. 2007. Analisis Ekonometrika dan Statistika dengan Eviews. Yogyakarta: UPP STIM YKPN.

Yuniarti, A. M. D. 2013. Pengaruh Kepemilikan Manajerial, Dividen, Profitabilitas dan Struktur Aset terhadap Kebijakan Hutang. Accounting Analysis Journal, 2(4), 447-454. https://doi.org/ISSN 2252-6765

Yunita, S., \& Aji, T. S. 2018. Pengaruh likuiditas, Tangibility, Growth Opportunity, Risiko Bisnis, dan Ukuran Perusahaan Terhadap Struktur Modal. Jurnal IImu Manajemen Volume 6 Nomor 4 - Jurusan Manajemen Fakultas Ekonomi Universitas Negeri Surabaya, 6, 409-416. 